\title{
Força de Preensão Palmar de Pacientes com Doença Renal Crônica em Terapia Dialítica
}

\author{
Fernandes, V.F.; Savegnago, D.; Fernandes, M.R.; Knijnik, L.M.; Leguisamo, \\ C.P.;
}

Apresentador: Vinícius Fornari Fernandes

\section{Resumo}

Introdução: Pacientes com doença renal crônica (DRC) em fase terminal submetidos à terapia de substituição renal por hemodiálise (HD) apresentam uma complexa síndrome com efeitos em diversos sistemas, entre eles, o sistema músculo esquelético. Este estudo teve como objetivo analisar a força de preensão palmar e correlacionar com o tempo de tratamento de pacientes com DRC submetidos à HD. Métodos: Estudo transversal que avaliou pacientes com DRC submetidos à HD no Hospital São Vicente de Paulo em Passo Fundo (RS). As avaliações foram realizadas individualmente através de um questionário clínico e sócio demográfico. Para avaliação da força muscular, foi utilizado o dinamômetro de preensão manual (capacidade de mensuração de 5 a $100 \mathrm{~kg}$ resolução $0,05 \mathrm{~kg}$ precisão $\pm 0,5 \%$ ) sobre os músculos flexores dos membros superiores. O projeto foi aprovado pelo Comitê de Ética em Pesquisa e está de acordo com a Declaração de Helsinki. Resultados: A amostra final do estudo foi de 27 pacientes (58,5 \pm 13 anos, 89\% homens). Comparando-se a força do membro superior esquerdo (MSE) com a força do membro superior direito (MSD) obtém-se, em newtons, $(2,29 \pm 0,32$ vs. $2,46 \pm 0,89 \mathrm{p}=0,513)$, respectivamente. $\mathrm{O}$ tempo de $\mathrm{HD}$ com força do MSE não apresentou relação significativa (Pearson $\mathrm{r}=-0,316 \mathrm{p}=0,109)$, porém houve uma correlação inversamente proporcional (Pearson $r=-0,433$ $\mathrm{p}=0,024)$ entre o tempo de HD com a força do MSD, demonstrando que os pacientes que há mais tempo estão em terapia renal substitutiva por HD tem menor força no MSD. As anormalidades músculo esqueléticas são numerosas e frequentes em pacientes doentes renais em particular daqueles mantidos por longo período de terapia de diálise renal. Sabe-se que pacientes em HD apresentam comprometimento na estrutura e na função muscular podendo manifestar pela atrofia e pela fraqueza muscular proximal. $\mathrm{O}$ aspecto que influência a diminuição da força muscular está associada às alterações no suprimento de energia das células musculares. As alterações nos sistemas metabólicos de produção de ATP diminuem a capacidade metabólica muscular basal em torno de $40 \%$ em paciente com IRC. Conclusão: Este estudo demonstrou que não há diferença estatisticamente significativa entre a força do MSE e do MSD nos pacientes com DRC em tratamento dialítico. Entretanto, o tempo de terapia renal substitutiva por hemodiálise é inversamente proporcional à força no MSD. Estudos futuros são necessários para melhor verificar tal associação.

\section{Referência:}

Fernandes, V.F.; Savegnago, D.; Fernandes, M.R.; Knijnik, L.M.; Leguisamo, C.P.;. Força de Preensão Palmar de Pacientes com Doença Renal Crônica em Terapia Dialítica. In: II Congresso Brasileiro de Medicina Hospitalar - II CBMH [= Blucher Medical Proceedings, vol.1, num.5] São Paulo: Editora Blucher, 2014. p.61

DOI 10.5151/medpro-II-cbmh-058 